\title{
Diagnostic yield and safety of capsule endoscopy
}

\author{
J. L. Matas, M. Asteinza' ${ }^{1}$ J. M. $\operatorname{Loscos}^{1}$, S. Fernández ${ }^{1}$, J. A. Ramírez-Armengol ${ }^{1}$ and M. Díaz-Rubio \\ Service of Digestive Diseases and ${ }^{1}$ Central Service of Endoscopy. Hospital Clínico San Carlos. Madrid, Spain
}

\begin{abstract}
Introduction: the capsule endoscopy (CE), from his approval, has become a first line diagnostic procedure for the study of the small bowel disease. The aim of this study is to report our experience since the implantation of this technique in our hospital.

Material and methods: retrospective review of the $\mathrm{CE}$ undertaken in Department of Endoscopy. There was gathered in every case the age, sex, motive of consultation, previous diagnostic procedures, capsule endoscopy findings and complication of the technique. One took to end a descriptive and analytical analysis.

Results: there was achieved a total of 416 explorations in 388 patients. The obscure gastrointestinal bleeding was the most frequent indication (83.30\%) followed by suspected Crohn's disease (7.5\%). Angiodisplasia was the endoscopic lesion more frequently detected $(42.2 \%)$, especially, in patients with digestive bleeding of obscure origin (OR $3.13 p<0.001$ ), followed by the flebectasia (10.6\%) and the ulcer suspicious of Crohn's disease (9.9\%). The global diagnostic yield as for the detection of injuries was $77.34 \%$ with a case of "not defecation of the capsule" and therefore need of laparotomy.

Conclusions: the capsule endoscopy is a technique consolidated and as his potential is known, his indications are extended. The obscure gastrointestinal bleeding is the most frequent indication and the angiodisplasia the most identified injury. Once known his diagnostic yield, larger studies are needed that assess the influence of capsule endoscopy on clinical outcoumes.
\end{abstract}

Key words: Capsule endoscopy. Obscure digestive bleeding. Occult gastrointestinal bleeding. Iron deficiency anemia. Crohn's disease.

Recibido: 31-05-05.

Aceptado: 17-05-06.

Correspondencia: José Luis Matas Navarro. Servicio de Aparato Digestivo. Hospital Clínico San Carlos. C/ Martín Lagos, s/n. 28040 Madrid. e-mail: jlmatas@wanadoo.es
Matas JL, Asteinza M, Loscos JM, Fernández S, Ramírez-Armengol JA, Díaz-Rubio. M. Diagnostic yield and safety of capsule endoscopy. Rev Esp Enferm Dig 2006; 98: 666-673.

\section{INTRODUCTION}

Capsule endoscopy (CE) has become a first-rate diagnostic procedure for the study of small bowel (SB)-related diseases (1-4). Since the technique was approved by the FDA (August 2001), its indications have varied as its potential diagnostic power and possible repercussions on subsequent therapeutic attitudes became known.

Nowadays the main indication of the CE is gastrointestinal bleeding of obscure origin (OGB), either in the form of occult bleeding (iron-deficiency anemia, positive occult blood in feces) or manifest bleeding where blood is visible, although no cause has been identified even after upper and lower endoscopic examinations (5-12).

Another confirmed indication is Crohn's disease (CD), although it may be primary contraindicated because of stenosis and it has the limitations of absence of histological confirmation and a difficult differential diagnosis with other conditions with similar characteristics $(12,13)$.

Other indications for $\mathrm{CE}$ are: SB tumors, predominant and generally discovered in the context of OGB, or suspected based on some imaging studies; gastrointestinal polyposis (14), malabsorption and eventually abdominal pain or symptoms of irritable bowel syndrome after some study on diagnostic effectiveness (3). In number of studies, CE has demonstrated better global results than other diagnostic methods, such as push enteroscopy, enteroclysis or conventional bowel follow-through, which also evaluate the SB $(13,15)$.

After approval by the European Agency in August 2001 , it began to be used in daily clinical practice at our hospital as a reference center. 
The aim of the present study is to report our experience with the $\mathrm{CE}$ since this procedure was implemented in our hospital, emphasizing its indications and diagnostic performance.

\section{MATERIAL AND METHODS}

A retrospective analysis of all CEs performed between November 2001 and January 2005 at the "Hospital Clínico San Carlos", Madrid, was carried out.

The following data were noted for each patient: age, sex, origin, reason for consultation, previous diagnostic procedures, endoscopic diagnosis, and incidents inherent to the technique.

All examinations were carried out using the M2A Given Imaging capsule following certain preparatory rules, including: fasting for 12 hours; no iron consumption for 10 days prior to the examination; no fruits, starch, vegetables or bread for 3 days before the test, and liquids only the day before.

As a general rule, no specific oral preparation was necessary, and prokinetics were administered to patients with founded suspicions of delayed passage, including bedridden and diabetic subjects. In each case, weight, height and waist measurements were taken and fed into the computer and recorder.

Guidelines followed for the examination were as follows:

1. Walk as much as possible and avoid sitting down for long periods or lying down.

2. Fasting for 3 hours, after which, some liquids (not dairy products) may be taken.

3. After 3 hours, a "light" snack may be taken with liquid.

4. 7 hours after capsule ingestion, the belt would be taken off and normal life could resume.

5. If the capsule has not been expelled within 1 week, the doctor must be consulted without undergoing any magnetic resonance procedures in the meantime.

All procedures were carried out with the written consent of the patient or legal representative where applicable, and the reading of studies was carried out by different doctors at the Endoscopy Department.

The program used for both the descriptive and analytical statistical studies was SPSS, version 12.0. Quantitative variables were expressed as mean $\pm \mathrm{SD}$ values; qualitative variables as percentages, and these variables were compared by means of a Chi-square test.

\section{RESULTS}

A total of 416 examinations were performed on 388 patients. Average patient age was $57.06 \pm 18.20$ years, with $50.5 \%$ being males and $49.5 \%$ females.

The reason for consultation was OGB [either in the form of occult bleeding (50\%) or in the form of manifest bleeding $(33.30 \%)$ ] in $83.30 \%$ of examinations. In the $7.5 \%$ of cases, CE was performed because of suspected $\mathrm{CD}$, and, in another $4.6 \%$, the cause was abdominal pain or diarrhea (Fig. 1). Regarding endoscopic diagnosis, angiodysplasia was the most commonly detected lesion (42.2\%), followed by phlebectasia $(10.6 \%)$ and ulcers suggestive of CD (9.9\%) (Table I); in $11.8 \%$ of examinations, no pathological findings were found, and, in $3.8 \%$, other diagnoses were established (two cecum neoplasms, 1 jejunal cancer, 1 carcinoid tumor, 1 Meckel's diverticulum, 2 Blue Rubber Bleb Nevus syndrome, 1 suspected case but not confirmed by histological study of Whipple's disease).

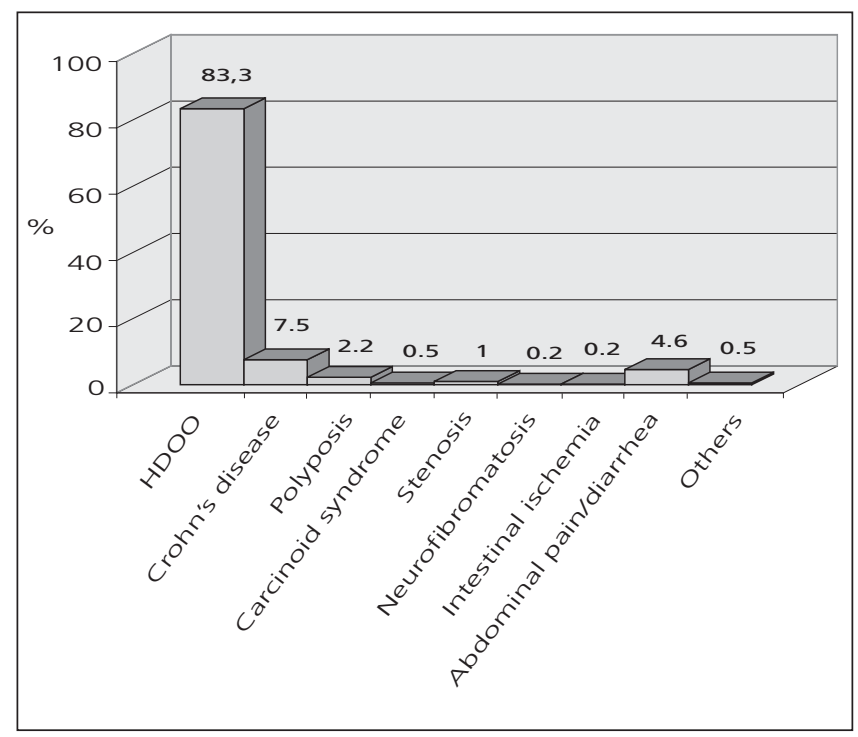

Fig. 1.- Reasons for consultation.

Motivos de consulta.

When the reason for consultation was OGB in the form of occult bleeding, angiodysplasia was the most frequently detected lesion (40.3\%). However, in $12.6 \%$ of cases the test was normal. In case of manifest bleeding, angiodysplasia was also the most commonly detected lesion $(55.9 \%)$, but in $5.9 \%$ of examinations CE showed normal findings. On a pooled examination of OGB, angiodysplasia was the most frequently observed lesion $[46.5 \%, \mathrm{p}<0.001 ;$ OR, $3.13(1.70-5.76)]$. It is important to report that when the reason for testing was OGB, blood was found in the gastrointestinal tract in $12.9 \%$ of examinations [p < 0.04, OR $3.24(0.98-10.78)]$.

On the analysis of cases with suspected $\mathrm{CD}$, the most common endoscopic findings were bleeding ulcers suggestive of CD (26\%) and angiodysplasia (26\%). In 22\% of examinations, the finding was normal. In the case of abdominal pain-irritable bowel-type symptoms (IBS), the examination was normal in 8 of them $(42.10 \%)$ and inconclusive in another 2 cases $(10.53 \%)$. 
Table I. Endoscopic diagnosis

\begin{tabular}{lclll}
\hline Diagnosis & $\%$ & Diagnosis & $\%$ & Diagnosis \\
\hline Phlebectasia & 10.6 & Lynphangiectasia & 5.3 & Blood in stomach \\
Edema/inflammation & 9.2 & Submucosal tumor & 2.4 & Blood in bulb \\
Erosion & 5.8 & Stenosis & 2.7 & Blood in jejunum \\
Crohn's ulcer & 9.9 & Colonic ulcer & 0.7 & Blood in ileum \\
Aphtas & 3.4 & Intestinal varices & 0.5 & Blood in colon \\
Xanthoma & 8.7 & Nodular lymphoid hyperplasia & 1.4 & Slow transit \\
Angiodysplasia & 42.2 & Gastric polyp & 1.2 & Inconclusive \\
Lipoma & 2.2 & Small-bowel polyp & 3.6 & Technical difficulties \\
GAVE & 0.7 & Villous atrophy & 1.7 & Normal examination \\
\hline
\end{tabular}

Other diagnoses: 3.8\%; GAVE: gastric antrum vascular ectasia.

Eleven cases $(2.7 \%)$ were diagnosed with stenosis of the small bowel, of which 3 patients were examined for iron-deficiency anemia, another 3 for OGB in the form of melena, 2 for suspected CD, another 2 for abdominal pain or diarrhea, and 1 for suspected stenosis. A total of 9 examinations was carried out for polypoid syndromes such as familial adenomatous polyposis (FAP) and PeutzJeghers syndrome (PJS). In 2 cases $(22.2 \%)$, gastric polyps were found; in one (11.1\%), duodenal polyps, in 5 (55.5\%), jejunal and ileal polyps; in $1(11.1 \%)$, HNL, and in another patient the examination was normal.

In $88.43 \%$ of all examinations, the ileum was identified, but the capsule had not reached the colon after finishing its recording in $13.01 \%$ of studies. The degradable capsule "Patency ${ }^{\mathrm{TM}}$ " was administered prior to the procedure in 5 patients with suspected stenosis of the SB: three patients $(60 \%)$ excreted the capsule normally and, there-

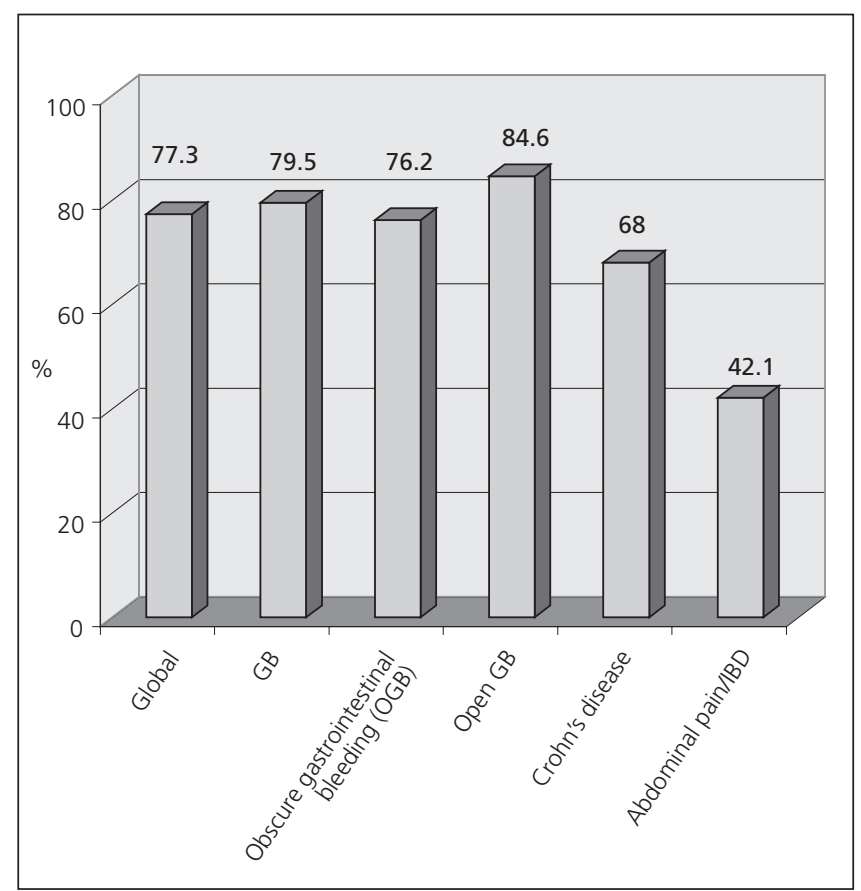

Fig. 2.- Effectiveness of capsule endoscopy in the detection of lesion. Rentabilidad de lesiones detectadas según indicaciones. fore, the study was subsequently carried out; another two patients $(40 \%)$ did not excrete it, and one of them suffered from acute abdominal pain, which evolved favorably with conservative treatment.

Overall effectiveness with regard to the detection of lesions was $77.34 \%$. In the case of OGB, the effectiveness was almost $80 \%$; in CD, $68 \%$ and in abdominal pain, $42 \%$. When we focus on findings that could be associated with symptoms overall effectiveness went down to $62 \%$, and in the same way decreased in the three previous indications $(66,44$ and $36 \%$ in OGB, CD, and abdominal pain, respectively) (Figs. 2 y 3 ).

There were 7 subjects $(1.69 \%)$ in whom the capsule remained within the stomach when the recording was over; most were bedridden patients, three of them with a history of gastric surgery (Billroth II) where the capsule remained in the afferent loop. There were 2 cases

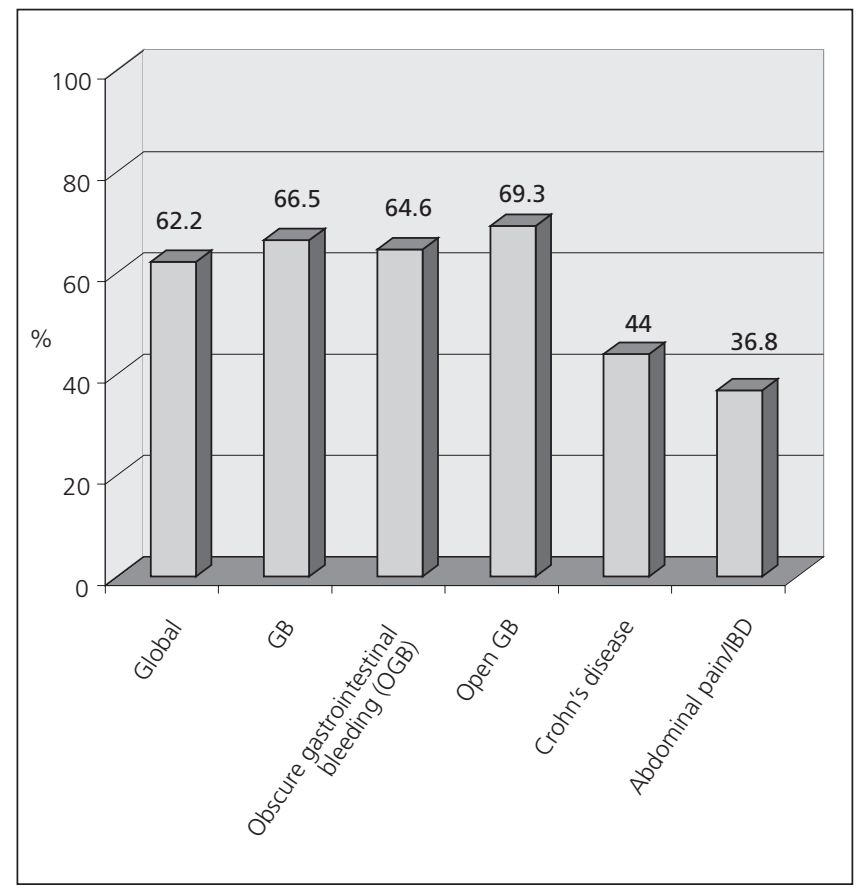

Fig. 3.- Effectiveness of capsule endoscopy based on its indications. Rentabilidad de lesiones diagnósticas según indicaciones. 
$(0.48 \%)$ of retention within the SB due to a stenosis of the intestinal loop, where the capsule could progress no further than the stenosis, and only one case was reported of "non-defecation of the capsule", which required a laparotomy.

Finally, we performed this examination in 13 patients $(3.35 \%)$ carrying pacemakers. No interference or malfunction was observed in any of these patients in either way between the capsule and the pacemaker.

\section{DISCUSSION}

$\mathrm{CE}$ is a first-rate procedure for the study of small-bowel diseases that has become increasingly consolidated. Its indications have increased as its potential diagnostic and subsequent repercussions have been demonstrated.

Nowadays, OGB, either in the form of chronic anemia or in the form of manifest bleeding, continues to be the main indication for CE. In our study, OGB represented the $83.30 \%$ of all indications, of which $33.30 \%$ corresponded to manifest bleeding.

Angiodysplasia was the most frequent finding in our study (42.2\% of total), corroborating the results from other studies, particularly when intestinal bleeding was the main symptom (16-18). It is a complex vascular lesion with a difficult diagnosis, which is attributed to $70-80 \%$ of SB hemorrhages. This percentage decreases when the study is carried out in younger patients.

In our study, the diagnostic effectiveness of $\mathrm{CE}$ was $77.34 \%$, which is in the range of results published by others (40 and $75 \%$ ). In the case of OGB, effectiveness varies between 55 and $75 \%$, and in the case of CD between 43 and $70 \%$ (in our study, 79.53 and 68\%, respectively) (12).

Regarding diagnostic effectiveness, certain clarifications and caution with results should be done. In practically all published studies, reference is made to lesions found whatever their nature and relationship with problem of the patient. Thus, the existence of blood in the gastrointestinal lumen is considered a positive finding even when no source of the bleeding could be identified. In this respect, it is essential to classify CE findings on the basis of the greater or lesser reliability with which the patient symptoms can be ascribed to these findings. The effectiveness of CE in OGB is clearly greater when bleeding is active when compared to occult bleeding (18-21). In tests performed in our hospital, the percentage of examinations with no findings was more than 2-fold for occult OGB as compared to manifest OGB. The same is the case with CD. In our study, overall effectiveness was almost $70 \%$, but if we analyze lesions described as suggestive of $\mathrm{CD}$ (erosion, aphtas, ulcer, villi erosion, SB stenosis) effectiveness decreases to $44 \%$. When the reason for consultation was abdominal pain, the objective effectiveness of CE was lower (in our study around $40 \%$ with an absence of findings in more than 50\% of CEs) (3).

In different studies $\mathrm{CE}$ has demonstrated one way or another that it is superior to other diagnostic procedures that also evaluate the SB -for instance, follow-through, enteroclysis, CT scans, and even push enteroscopy $(7,8,12,13,15,22)$.

$\mathrm{CE}$ is quite a safe procedure allowing a complete view of the SB in a large percentage ( $88.43 \%$ in our study) of subjects; in quite a high percentage the capsule reaches the colon before the recording had finished $(86.99 \%$ in our study), thus documenting in some cases a condition at this level when the gastrointestinal lumen does not have much fecal content $(2,23)$.

Complications inherent to the technique are infrequent, but $\mathrm{CE}$ retention in the $\mathrm{SB}$ has been described (around 1\% non-defecation of the capsule), in some cases, resulting in acute abdominal pain and, consequently, requiring urgent laparotomy (24). In our patients, one case of acute abdominal pain occurred, but it has been published a study in which it took place in $13.46 \%$ of laparotomies (25). The arrival of the Patency degradable capsule is aimed to prevent problems in patients with suspected stenosis, where $\mathrm{CE}$ is contraindicated.

We had not problems either in patients who had undergone previous abdominal surgery or in patients with pacemakers, which initially was considered a contraindication for the procedure. However, more recently, it has been demonstrated the absence of interference or malfunction of the pacemaker during the prodecure $(26,27)$. In our study we carried out 13 examinations on patients with pacemakers with no problems whatever.

Now that the diagnostic efficiency and safety of the capsule has been demonstrated, its clinical effectiveness regarding its relative use in later therapeutic interventions remains to be demonstrated. There are studies on this matter involving a small number of patients and with dissimilar results $(9,15,28,29)$.

However, large scale studies on the clinical effectiveness of CE using a precise methodology are needed to allow its conclusive consolidation in clinical practice.

\section{REFERENCES}

1. Gay G, Delvaux M, Rey JF. The role of video capsule endoscopy in the diagnosis of digestive diseases: a review of current possibilities. Endoscopy 2004; 36 (10): 913-20.

2. Maieron A, Hubner D, Blaha B, Deutsch C, Schickmair T, Ziachehabi A, et al. Multicenter retrospective evaluation of capsule endoscopy in clinical routine. Endoscopy 2004; 36 (10): 864-8.

3. Fireman Z, Eliakim R, Adler S, Scapa E. Capsule endoscopy in real life: a four-center experience of 160 consecutive patientes in Israel. Eur J Gastroenterol Hepatol 2004; 16 (9): 927-31.

4. Arnott ID, Lo SK. The clinical utility of vireles capsule endoscopy. Dig Dis Sci 2004; 49 (6): 893-901.

5. Apostolopoulos P, Papanikolaou IS, Kalantzis N. Capsule endoscopy in obscure occult vs. obscure overt GI bleeding. Gastrointest Endosc 2005; 61 (1): 187-8.

6. Fireman Z, Kopelman Y. The role of video capsule endoscopy in the evaluation of iron deficiency anaemia. Dig Liver Dis 2004; 36 (2): $97-$ 102.

7. Mitchell SH, Schaefer DC, Dubagunta S. A new of occult and obscure gastrointestinal bleeding. Am Fam Physician 2004; 69 (4): 875-81.

8. Lewis B, Goldfarb N. Review article: The advent of capsule endos- 
copy-a not-so-futuristic approach to obscure gastrointestinal bleeding. Aliment Pharmacol Ther 2003; 17 (9): 1085-96.

9. Delvaux M, Fassler I, Gay G. Clinical usefulness of the endoscopic video capsule as the initial intestinal investigation in patients with obscure digestive bleeding: validation of a diagnostic strategy based on the patient outcome after 12 months. Endoscopy 2004; 36 (12): 1067-73.

10. Caunedo Álvarez A, Rodríguez-Téllez M, Barroso Relinque N, García Montes JM, Pellicer Bautista FL, Herrerías Gutiérrez JM. Role of capsule endoscopy in the management of patients with obscure gastrointestinal bleeding. Rev Esp Enferm Dig 2002; 94 (8): 482-92.

11. Martínez Ares D, González Conde B, Souto Ruzo J, Vázquez Millán MA, Estévez Prieto E, Alonso Aguirre P, et al. Obscure gastrointestinal bleeding: a complication of radiation enteritis diagnosed by wireless capsule endoscopy. Rev Esp Enferm Dig 2004; 96 (2): 132-7.

12. Ruano-Ravina A, Rey-Liste T. Effectiveness of endoscopic capsule for the detection of small-bowel bleeding of unknown origin and for the diagnosis of Crohn's disease. Med Clin (Barc) 2004; 123 (2): 70-6.

13. Eliakim R, Suissa A, Yassin K, Katz D, Fischer D. Wireless capsule video endoscopy compared to barium follow-through and computerised tomography in patients with suspected Crohn'disease-final report. Dig Liver Dis 2004; 36 (8): 519-22.

14. Schulmann K, Hollerbach S, Kraus K, Willert J, Vogel T, Moslein G, et al. Feasibility and diagnostic utility of video capsule endoscopy for the detection of small bowel polyps in patients with hereditary polyposis syndromes. Am J Gastroenterol 2005; 100 (1): 27-37.

15. Mata A, Bordas JM, Feu F, Ginés A, Pellise M, Fernández-Esparrach $\mathrm{G}$, et al. Wireless capsule endoscopy in patients with obscure gastrointestinal bleeding: a comparative study with push enteroscopy. Aliment Pharmacol Ther 2004; 20 (2): 189-94.

16. Costamagna G, Shah SK, Riccioni ME, Foschia F, Mutignani M, Perri $\mathrm{V}$, et al. A prospective trial comparing small bowel radiographs and video capsule endoscopy for suspected small bowel disease. Gastroenterology 2002; 1234: 999-1005.

17. Mylonaki M, Fristcher-Ravens A, Swain P. Wireless capsule endoscopy: a comparison with push enteroscopy in chronic gastrointestinal bleeding. Gut 2003; 52: 1122-6.
18. Pennazio M, Santucci R, Rondonotti E, Abbiati C, Beccari G, Rossini $\mathrm{FP}$, et al. Outcome of patients with obscure gastrointestinal bleeding after capsule endoscopy: Report of 100 consecutive cases. Gastroenterology 2004; 126: 643-53.

19. Jensen DM. Current diagnosis and treatment of severe obscure gastrointestinal bleeding. Gastrointest Endosc 2003; 58: 256-67.

20. Soares JM, Lopes L, Villasboas G. Evolution of phenotypic expression of small bowel polyps in Peutz Jeghers syndrome pedigrees with wireless capsule endoscopy. Endoscopy 2002; 34 (Supl. II): A275.

21. Caunedo A, Rodríguez-Tellez M, García-Montes JM, Gómez-Rodríguez BJ, Guerrero J, Herrerías JM, et al. Utilidad de la cápsula endoscópica en pacientes con sospecha de patología de intestino delgado. Rev Esp Enferm Dig 2004; 96 (1): 10-21.

22. Fireman Z, Friedman S. Diagnostic yield of capsule endoscopy in obscure gastrointestinal bleeding. Digestion 2004; 70 (3): 201-6.

23. Napierkowski JJ, Maydonovitch CL, Belle LS, Brand WT Jr, Holtzmuller KC. Wireless capsule endoscopy in a community gastroenterology practice. J Clin Gastroenterol 2005; 39 (1): 36-41.

24. Barkin J, Friedman S. Wireless capsule endoscopy requiring surgical intervention. $2^{\text {nd }}$ Conference on capsule endoscopy, 171. Berlin: Ed. Given Imaging; 2003.

25. Sears DM, Avots-Avotins A, Culp K, Gavin MW. Frequency and clinical outcome of capsule retention during capsule endoscopy for GI bleeding of obscure origin. Gastrointest Endosc 2004; 60 (5): 822-7.

26. De Palma GD, Rega M, Puzzielo A, Aprea G, Ciacci C, Castiglione F, et al. Capsule endoscopy is safe and effective after small-bowel resection. Gastrointest Endosc 2004; 60 (1): 135-8.

27. Fernández Díez S, Ramírez Armengol JA. Cardiac pacemaker: a real contraindication for capsule endoscopy? $2^{\text {nd }}$ Conference on capsule endoscopy, 137. Berlin: Ed. Given Imaging; 2003.

28. Rastogi A, Schoen RE, Slivka A. Diagnostic yield and clinical outcomes of capsule endoscopy. Gastrointest Endosc 2004; 60 (6): 959-64.

29. Ben Soussan E, Antonietti M, Herve S, Savoye G, Ramírez S, Lecleire S, et al. Diagnostic yield and therapeutic implications of capsule endoscopy in obscure gastrointestinal bleeding. Gastroenterol Clin Biol 2004; 28 (11): 1068-73. 